\title{
Appendiceal Mucocele with Chronic Appendicitis: A Rare Case Report
}

\author{
Mahendra Singh $^{1}$, Jaivijay Tiwari ${ }^{2 *}$, Neelima Verma ${ }^{3}$ \\ ${ }^{1}$ Prof. \& Head, Department of Pathology, GSVM Medical College, Kanpur, India \\ 2Junior Resident III, Department of Pathology, GSVM Medical College, Kanpur, India \\ ${ }^{3}$ Associate Professor, Department of Pathology, GSVM Medical College, Kanpur, India
}

*Address for Correspondence: Dr. Jaivijay Tiwari, Junior Resident III, Department of Pathology, GSVM Medical College, Kanpur, U.P, India

E-mail: Jaivijay9415@gmail.com

Received: 23 Jan 2020/ Revised: 28 Mar 2020/ Accepted: 26 Apr 2020

\begin{abstract}
Background- Appendiceal mucocele is a rare disorder but its clinical signs exactly match with acute appendicitis. Sometimes, it appears accidental. Accurate and sensitive diagnostic method before surgery is the prerequisite of selection of appropriate surgical treatment to prevent intra-operative and postoperative complications. If untreated or misguided, then mucocele symptoms may appear in the peritoneal cavity, ultimately it transformed into a dangerous form of the disease called pseudomyxoma peritonei. Ultrasonography (USG) and computed tomography (CT) are the two best-known methods utilized for this purpose.

Methods-A proper surgical wards registries, operation theatre and histopathology department were reviewed to retrieve cases of appendiceal mucocele. The patient's with the disorder had medical report had been studied to check out their associated factors such as demographic, clinical, radiological and histopathological data.

Results- Mucocele of the appendix is a bulged portion of the appendix by mucous following the mucinous, mucinoma cystadenoma (63\%), mucosal hyperplasia (25\%), mucinous cystadenocarcinoma (11\%), ultimately result in retention cyst mass formation. The basic reason of Mucocele occurrence is due to the lumen blockage by endometriosis or carcinoid tumour at the specified location. Approximately, 50\% appendicitis cases were observed, while examinations through radiological method or by following the surgical methods.

Conclusion- This study concluded that the appendiceal mucocele is easily comparable to acute appendicitis. Preoperative diagnosis is preferable, an important surgical methodology, USG and CT are the two best known methods utilized for this purpose.
\end{abstract}

Key-words: Carcinoma, Dysplasia, Endoscopy, Hyperplasia, Intussusception, Pseudomyxoma peritonei

\section{INTRODUCTION}

The term mucocele appendix was coined by Karl Freinherrvon Rokitansky in $1942^{[1-3]}$. Mucocele appendix is an obstructive disorder, resulted due to an extra proliferation of epithelial tissues of the abdominal region, which result in the appendix dilation because of intraluminal accumulation of mucilaginous fluids. But it is a rare disorder. The reported incidence of this disorder was $0.2 \%$ to $0.7 \%$ only from appendectomy specimens [4-6]

\section{How to cite this article}

Singh M, Tiwari J. Appendiceal Mucocele with Chronic Appendicitis: A Rare Case Report. SSR Inst. Int. J. Life Sci., 2020; 6(3): 2552-2556.

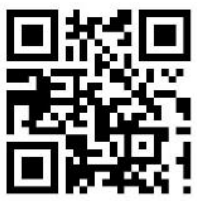

The frequency of the disease equally appeared in both the sex, as observed between the $5^{\text {th }}$ and $7^{\text {th }}$ decades of life ${ }^{[7]}$.

Mucocele appendix is further classified into four types according to the histopathological examinations: a) Retention cyst, b) mucosal hyperplasia, c) mucinous cystadenoma and d) mucinous cystadenocarcinoma ${ }^{[8]}$. But the worst thing about this disorder is lack of initial sign of appearance, only diagnosed when this disease approaches to its advanced level. It means mucocele appendix doesn't have any clinical sign of appearance. Sometimes, a patient with appendiceal mucocele have feel pain in a lower right quadrant of the abdomen; that's why mistakenly diagnosed as acute appendicitis. If untreated or misguided, then mucocele symptoms may be appeared in the peritoneal cavity, ultimately it 
transformed into a dangerous form of the disease called pseudomyxoma peritonei, which has a high mortality rate ${ }^{[8]}$. Its more advanced form is termed as Jelly belly Syndrome ${ }^{[9]}$ in which peritoneal cavity has only mucinous like fluids. The main objective of the current study is to investigate the appendiceal lesions, through the USG as a primary diagnostic tool. Instead of this, an extensive preoperative investigation, and their diagnosis in a patient with appendicitis disorder remains a difficult task, but detectable only at the time of surgery.

\section{CASE PRESENTATION}

The present study is a case of 46 -year-old person, who was suffered from chronic appendicitis admitted in the Department of Emergency, GSVM Medical College, Kanpur to confirmation of appendicitis in an admitted patient had found abdominal pain at the lower right portion, nausea, fever and vomiting like symptoms are also reported.

These reported symptoms appeared at 4 months prior and then again sub-sided after medicine intake, but the treatment is not perfect because the same symptoms appear 2 days prior repeatedly and the condition of the admitted person has become worse, that's why that person must undergo for further medical checkup by the surgeon and if the symptoms like palpation tenderness was noted at Mcburneys point, abdominal muscles appeared to moderately rigid and rebound tenderness, then it is serious. For more confirmation, the patient body temperature was regularly checked, its measured temperature is $37.8^{\circ} \mathrm{C}$ and total leucocyte count, (TLC), 14400 cells $/ \mathrm{mm}^{3}$ was noted. From abdominal USG images confirmed the loops of the intestine puffed with the gases in the lower right region of abdomen. After diagnosed the patient with acute appendicitis, should undergo open appendectomy, a surgical removal of the appendix. An observed area of the swollen appendix would be $4 \times 3 \times 2 \mathrm{~cm}$, noted at the time of surgery. At the swollen portion of the appendix, a cystic mass $(1 \times 0.8 \times 0.7$ $\mathrm{cm}$ ) of fluids was appeared with no perforation. No free fluids were accumulated in the peritoneal cavity of the stomach. A fluid like mucin is accumulated at the inflamed portion of the appendix, medically it is known as mucocele of the appendix was diagnosed. Thus, the appendectomy surgery must be followed due to cystic mass of fluids is appeared only at the tip instead of the based region of the appendix. But the stage of appendicitis has not appeared chronic it may be at acute stage due to the following reasons: Size of lymph nodes is not increased. There was no complication in the postoperative period. Specimens send for histopathological examination in the pathology department. For histopathological examination, grossly specimen received in one labelled vial mentioned as appendix. A piece of tubular tissue was taken as specimen of $4 \times 3 \times 2 \mathrm{~cm}$ diameter. The tissue collected from the appendicular tip has thickened globular area of $1 \times 0.8 \times 0.7 \mathrm{~cm}$. The tissue collected have outer surface which is smooth and shiny with fibro-fatty adhesions with attached mesentery, it's one end is open and the other end is closed. For further study of the thickened globular area, this is expected to have mucoid like fluid. Microscopy Fig. 1 and Fig. 2 reveals appendiceal mucosal mucinous hyperplasia, there is cystic dilatation of lumen. Lumen shows mucinous secretion. There is mild inflammatory cell infiltrate in the layers of the appendix. These Microscopic findings are suggestive of appendiceal mucocele with chronic appendicitis.

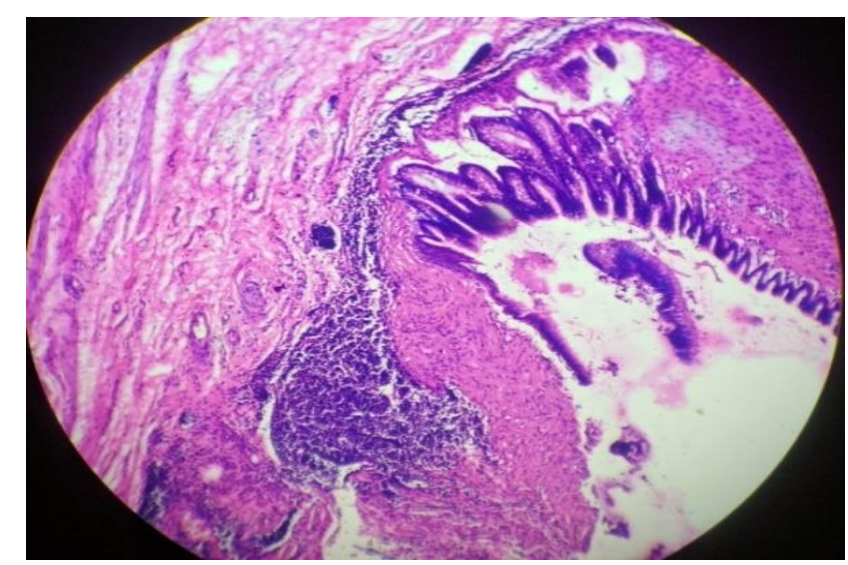

A- Hematoxylin \& Eosin Stain (shows lymphoid follicle and mucinous hyperplasia)

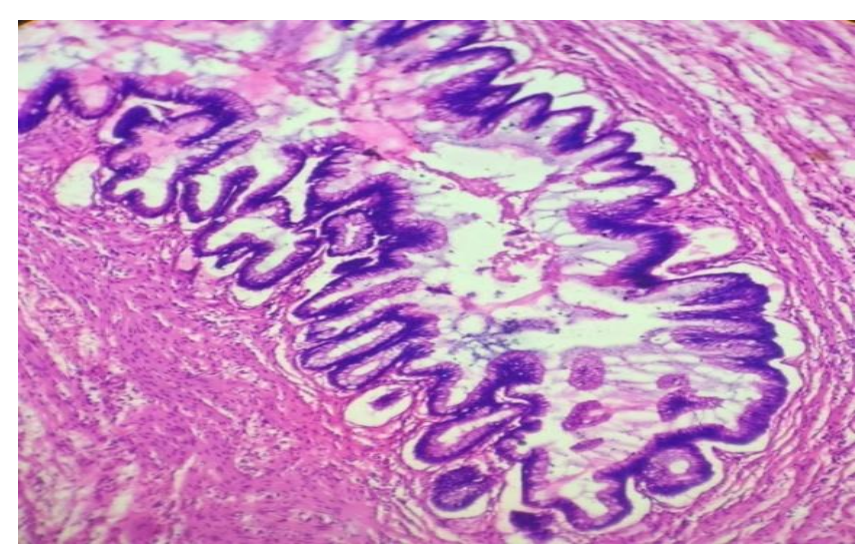

B- Hematoxylin \& Eosin Stain (shows mucous filled appendix)

Fig. 1: Microscopic view of mucocele of appendix 10x Magnification 


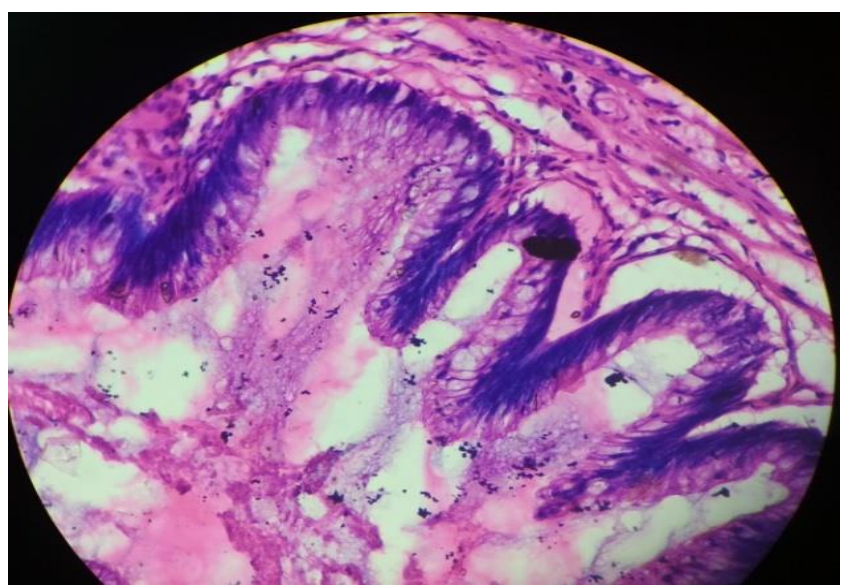

A- Hematoxylin \& Eosin Stain (shows mucinous hyperplasia)

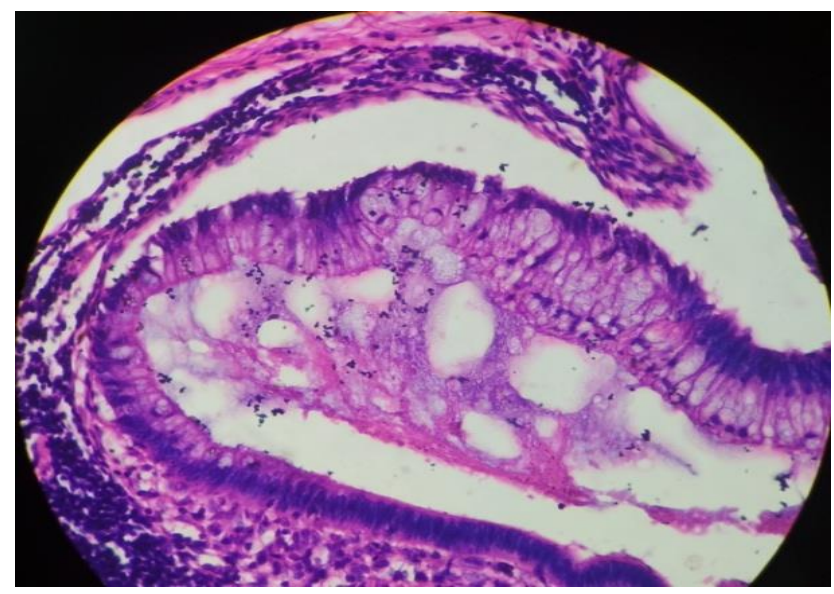

B- Hematoxylin \& Eosin Stain (shows mucinous hyperplasia along with mild inflammatory cell infiltrate and mucinous secretion)

Fig. 2: Microscopic view of mucocele of appendix 40x Magnification

\section{DISCUSSION}

Mucocele of the appendix is a bulged portion of appendix by mucous following the mucinous, mucinoma cystadenoma (63\%), mucosal hyperplasia (25\%), mucinous cystadenocarcinoma (11\%), ultimately result in retention cyst mass formation ${ }^{[10]}$. The basic reason for mucocele occurrence is due to the lumen blockage by endometriosis or carcinoid tumour at the specified location. Approximately, 50\% appendicitis cases were observed while examinations through radiological method or by following the surgical methods. Most studies reported to confirm its prevalence among women, while some studies also demonstrate its higher incidence among men ${ }^{[11,12]}$.

Appendiceal mucocele classification is based on histological features of lumen obstruction ${ }^{[13]}$.
1. Simple mucocele (Inflammatory, obstructive, or retention cyst)- Blockage and inflammation in appendicular epithelial tissues were resulted due to destruction in epithelial cells but no incidence of hyperplasia or mucosal atypia was reported.

2. Hyperplastic Mucocele- An abnormal growth of appendicular tissues inside the lining of the colon which results in appendix dilations.

3. Mucinous cystadenoma- It is an appendix neoplasm with dysplastic epithelium proliferation, similar to colon adenomatous polyps.

4. Mucinous cystadenocarcinoma- It is a abnormal growth and proliferation results called cellular dysplasia with stromal invasion, besides having muscular i.e. mucosae.

The most common clinical sign includes extreme pain in the lower right portion of appendicular tissues, which resulted in bowel habits or inflamed mass such as diarrhea, constipation, or narrowing of the stool ${ }^{[14]}$ as observed in rectal bleeding and sign of intussusceptions of the intestinal colon. Preoperative diagnosis, a surgical method, of appendicular mucocele is crucial so as, to prevent from peritoneal dissemination, intra-operative and post-operative complications and repeated surgery [15,16]. USG, or CT and Colonoscopy are commonly used for diagnostic purposes of appendicitis. This USG methodology is preferable imaging procedure in a patient with acute abdominal pain. With the help of USG, it can be easy to distinguish mucocele and acute appendicitis conditions. The distinguishing pattern can be observed closely increase of acute appendicitis, that is based on the threshold size of the outer diameter of the appendix is approx. $6 \mathrm{~mm}$, while it will be more increase of mucocele, also described Receiver operative characteristics (ROC), showing (83\%) sensitivity and (92\%) specificity, it means USG defined the disease diagnosis with good reproducibility and appendicitis is at prominent stage ${ }^{[17-20]}$. In addition, CT is considered the most reproducible and reliable method of diagnostics in this case study. As compared to USG, following CT method is more preferable because its diagnostic capacity to detect the mucocele disorder is higher. Symptoms like cystic dilatation and wall calcification appeared, if the appendix lumen size is $>1.3 \mathrm{~cm}$, and enlargement of appendiceal cavity takes place with the liberation of yellowish mucous from the cavity, that can be easily visualized through the Colonoscopy. 


\section{CONCLUSIONS}

This study concludes that the appendiceal mucocele is easily comparable to acute appendicitis. Preoperative diagnosis is preferable, an important surgical methodology to prevent severe intra-operative and postoperative complications in a patient with acute appendicitis. Ultrasonography and computed tomography are the two best-known methods utilized for this purpose.

The viewpoint of the study, focus on those patients with age of $>45$ year, who suffers from acute appendicitis must undergo for CT and open surgery instead of following laparoscopic surgery.

\section{CONTRIBUTION OF AUTHORS}

Research concept- Prof. Mahendra Singh, Dr. Jaivijay

Tiwari

Research design- Dr. Jaivijay Tiwari

Supervision- Prof. Mahendra Singh, Dr. Neelima Verma

Materials- Dr. Jaivijay Tiwari

Data collection- Dr. Jaivijay Tiwari

Data analysis and Interpretation- Prof. Mahendra Singh, Dr. Jaivijay Tiwari

Literature search- Dr. Jaivijay Tiwari

Writing article- Dr. Jaivijay Tiwari

Critical review- Prof. Mahendra Singh

Article editing- Dr. Jaivijay Tiwari

Final approval- Prof. Mahendra Singh

\section{REFERENCES}

[1] Ferraz de Campos FP. The Dawn of Modern Pathology. Autops Case Rep., 2016; 6(1): 1-5.

[2] Rokitansky CF. A Manual of Pathological Anatomy, Vol 2, Blanchard \& Lea, Philadel phia, Pa, USA, 1855.

[3] Rangarajan M, Palanivelu C, Kavalakat AJ, Parthasarathi R. Laparoscopic appendectomy for mucocele of the appendix: Report of 8 cases. Indian J. Gastroenterol., 2006; 25 (5): 256-57.

[4] Rangarajan M, Palanivelu C, Kavalakat AJ, Parthasarathi R. Laparoscopic appendectomy for mucocele of the appendix: Report of 8 cases. Indian J. Gastroenterol., 2006; 25 (5): 256-57.

[5] Marudanayagam R, Williams GT, Rees BI. Review of the pathological results of 2660 appendicectomy specimens. J Gastroenterol., 2006; 41(8): 745-49.

[6] Tovar RJ, Teruel DG, Gastineires VM, Dehesa As, Quindos PL, et al. Mucocele of the appendix. World J Surg., 2007; 31(3): 542-48.
[7] Smeenk RM, van Velthuysen ML, Verwaal VJ, Zoetmulder FA. Appendiceal neoplasms and pseudomyxoma peritonei: A population based study. Eur. J. Surg. Oncol., 2008; 34(2): 196-201.

[8] Sugarbaker PH. Appendiceal epithelial neoplasms and pseudomyxoma peritonei, a distinct clinical entity with distinct treatments. In: Bland KJ, Buchler MW, Csendes A, Garden OY. Saar MG, Wong J (eds). General Surgery. Principles and International Practice. London-Limited: Springer, 2009; 885-93.

[9] Moran BJ, Cecil TD. The etiology, clinical presentation, and management of pseudomyxoma peritonei. Surg Oncol Clin N Am., 2003; 12(3): 585603.

[10]Higa E, Rosai J, Pizzimbono CA, Wise L. Mucosal hyperplasia, mucinous cystadenoma, and mucinous cystadenocarcinoma of the appendix. A reevaluation of appendiceal mucocele. Cancer, 1973; 32(6): 1525-41.

[11]Ruiz-Tovar J, Teruel DG, Castiñeiras VM, Dehesa AS, Quindós PL, et al. Mucocele of the appendix. World J Surg., 2007; 31(3): 542-48.

[12] Kim SH, Lim HK, Lee WJ, Lim JH, Byun JY. Mucocele of the appendix: ultrasonographic and $\mathrm{CT}$ findings. Abdom Imaging, 1998; 23(3): 292-96.

[13]Kumar S, Jasujab P. Appendiceal mucocele-A rare case report. Int J Surg Case Rep., 2019; 58: 21-25. doi: 10.1016/j.ijscr.2019.04.008.

[14]Simon S. Signs and Symptoms of Colorectal Cancer [Internet]. February 18, 2020. Available from: https://www.cancer.org/latest-news/signs-andsymptoms-of-colon-cancer.html.

[15]Aho AJ, Heinonen R, Laurén P. Benign and malignant mucocele of the appendix. Histological types and prognosis. Acta Chir Scand., 1973; 139(4): 392-400.

[16]Sugarbaker PH. Appendiceal epithelial neoplasms and pseudomyxoma peritonei, a distinct clinical entity with distinct treatments, in: K.J. Bland, M.W. Buchler, A. Csendes, O.Y. Garden, M.G. Saar, J. Wong (Eds.), General Surgery. Principles and International Practice. Springer, London-Limited, 2009, pp. 885-93.

[17]Dhage-Ivatury $S$, Sugarbaker PH. Update on the surgical approach to mucocele of the appendix. J Am Coll Surg., 2006; 202(4): 680-84.

[18] Lien WC, Huang SP, Chi CL, et al. Appendiceal outer diameter as an indicator for differentiating 
appendiceal mucocele from appendicitis. Am J Emerg Med., 2006; 24(7): 801-05.

[19]Francica G, Lapiccirella G, Giardiello C, et al. Giant mucocele of the appendix: clinical and imaging findings in 3 cases. J Ultrasound Med., 2006; 25(5): 643-48. doi: 10.7863/jum.2006.25.5.643.
[20]Birnbaum BA, Wilson SR. Appendicitis at the millennium. Radiol., 2000; 215(2): 337-48. doi: 10.1148/radiology.215.2.r00ma24337.

[21]Sasaki K, Ishida H, Komatsuda T, et al. Appendiceal mucocele: sonographic findings. Abdom Imaging. 2003; 28(1): 15-18. doi: 10.1007/s00261-001-01758. 